Stoa

Vol. 2, No. 3, 2011, pp. 7-26

ISSN en trámite.

\title{
¿CÓMO DEBE SER UNA (NUEVA) TEORÍA SOCIAL PARA ENCUADRAR EL DESARROLLO SUSTENTABLE?
}

\author{
LEANDRO RODRIGUEZ MEDINA \\ Departamento de Relaciones \\ Internacionales y Ciencia Política \\ Universidad de las Américas Puebla \\ leandro.rodriguez@udlap.mx
}

RESUMEN: La teoría social y política ha subestimado, cuando no abiertamente ignorado, dos tipos de relaciones que podríamos denominar no-sociales en su sentido tradicional. La primera de esas relaciones incluye el vínculo entre humanos y no-humanos entendidos estos últimos como objetos y tecnología. La segunda de esas relaciones es la que conecta a humanos con la naturaleza. La ausencia de las primeras impide observar el entramado material que da sostén en el tiempo y en el espacio a las relaciones sociales y políticas. La ausencia de las segundas da lugar a una visión de la sociedad como producto humano exclusivamente y, en más de un sentido, superior a otras manifestaciones naturales. El presente artículo busca comenzar a llenar ambos vacíos a través de la exploración de una nueva teoría social que, influida por los estudios de la ciencia y la tecnología, permita incorporar la 'naturaleza' y la 'tecnología' de manera más adecuada para que el problema del desarrollo sustentable tenga plena cabida en las ciencias sociales contemporáneas.

PALABRAS CLAVE: desarrollo sustentable - teoría social - Teoría de Actor-red - tecnología - naturaleza

SUMMARY: Social and political theory has underestimated, or ignored althogether, two types of relationships that can be considered, a priori, non social in their traditional sense. The first of those relationships includes the nexus between humans and nonhumans, being the later objects and technology in a broad sense. The second type of relationship connects humans with nature. While the absence of the first one impedes to observe the material network that sustains in time and space every social and political bond, the absence of the second ones produces an idea of society as a human project exclusively, one that, in many ways, appears as superior to other natural manifestations. This article aims to fill this gap by proposing an outline of a new social and political theory that, influenced by Science and Technology Studies, brings nature 
and technology to the foreground in order to understand the problem of sustainable development within contemporary social sciences' frameworks.

KEY WORDS: sustainable development - social theory - Actor-network theory - techno$\log$ - nature

\section{Introducción}

El presente capítulo pretende esbozar los lineamientos generales que una teoría social debería tener para poder dar cuenta del desarrollo sustentable como problema inherente a la sociabilidad contemporánea y no sólo como un fenómeno periférico e, incluso, anómalo. Para lograrlo, hemos estructurado el texto en tres partes. En la primera, siguiendo los planteos de Latour $(1988,2005)$, analizaremos qué aspectos de la teoría social tradicional deben cuestionarse para comenzar la tarea de encontrar una nueva manera de entender la sociedad. En la segunda, nos abocaremos en las principales consecuencias que esta nueva teoría social, ejemplificada en lo que se conoce como teoría de actorred (TAR), tiene para la comprensión del desarrollo sustentable. En particular se ahondará en la importancia que lo no-humano tiene para el entendimiento de la sociedad e inclusive de las relaciones humanas que la constituyen. ${ }^{1}$ Finalmente, la tercera sección presenta las conclusiones de este capítulo, abriendo interrogantes fecundos para la investigación social pero también replanteando el papel -y el ejercicio- de la crítica social en la actualidad.

\section{Cinco incertidumbres sobre la teoría social}

Desde comienzos de los años 80 ha habido en los estudios de la ciencia un giro que desplazó las preguntas sobre el conocimiento del plano epistemológico al sociológico, con un énfasis no sólo en la organización de la producción de saberes sino también en el papel que la materialidad tiene en dicho proceso. Es posible concebir el pionero estudio de Thomas Kuhn (1962) como la puerta hacia una concepción pragmática y empírica de la ciencia que se enfocó en

\footnotetext{
${ }^{1}$ Una concepción diferente de asociación entre lo humano y lo no-humano es lo que hace que TAR sea una alternativa en teoría social a los tres modelos 'tradicionales': el marxismo (donde lo material es infraestructural y determinante), la teoría crítica -Bourdieu- y de la estructuración -Giddens- (donde lo material es reflejo de relaciones sociales preexistentes) y el interaccionismo simbólico (donde lo material es sólo el escenario en el que los actores humanos desarrollan sus roles. Para mayores detalles véase Latour 2005, pp. 82-86.
} 
las condiciones de consenso dentro de las comunidades científicas y su impacto epistemológico. En esa línea sociológica, la Escuela de Edimburgo dio un paso más al proponer la tesis de la simetría según la cual tanto el conocimiento falso como el verdadero tienen, en última instancia, una explicación que descansa, en mayor o menor medida, en las condiciones sociales de los productores de dicho conocimiento. En otras palabras, la Escuela de Edimburgo sostenía que aún lo que creemos verdadero no deja de ser, precisamente, una creencia y, como tal, está anclada a su contexto social de producción, circulación y aceptación. La tesis de la simetría escondía una posición ontológica muy particular. Mientras se defendía una posición relativista para dar cuenta del conocimiento científico, se mantenía un realismo fuerte para entender la sociedad. El átomo o el gen eran, en última instancia, construcciones sociales, pero las clases sociales o grupos eran entidades que existían independientemente del entorno. Esta denuncia dio origen a la teoría de la hipersimetría.

La hipersimetría, que fue esgrimida desde sus orígenes por los pioneros de la teoría de actor red, sostiene que la posición relativista debe sostenerse para ambas dimensiones de la explicación. Si los genes y la teoría de la evolución son productos de la Inglaterra victoriana, la Inglaterra victoriana es producto también de los genes y la teoría de la evolución. Dicho en términos más generales, si la sociedad explica la naturaleza, no es menos cierto que la naturaleza debe ser un elemento clave en la explicación de lo social. La consecuencia directa, contra-intuitiva y desafiante es obvia: seres humanos y entidades no-humanas (desde piedras hasta aviones, pasando por las hormonas y los gobiernos) deben ser tratados, desde un punto de vista metafísico, en iguales términos. No hay razón para que los humanos -y lo social- tengan predominio en ninguna explicación científica o tecnológica.

Desde sus comienzos, la TAR motivó controversias y debates profundos al interior de la disciplina ahora conocida como Estudios de Ciencia y Tecnología (ECT). Pero lo cierto es que, en la medida en que esa teoría cuestionaba el alcance de las explicaciones sociológicas de la ciencia, también ponía en entredicho la concepción de la sociedad defendida por la sociología y varias disciplinas subsidiarias, como la ciencia política o la economía. En última instancia, si TAR había revolucionado la comprensión de la ciencia, su desarrollo y organización, también estaba dispuesta a hacer lo mismo con la sociedad, su 
entramado y devenir histórico. El texto que, de alguna manera, dio estructura a la crítica de TAR a la sociología clásica fue Reassembling the Social. An Introduction to Actor-Network Theory que en 2005 publicó Bruno Latour. En dicha obra, se esgrimen cinco incertidumbres que la teoría sociológica clásica ha escondido detrás de supuestos ontológicos y epistemológicos que los estudios de la ciencia - entre otras disciplinas - parecen haber cuestionado profundamente. A continuación propongo un breve resumen de los mismos, para en la sección posterior adentrarnos en sus implicaciones para la(s) teoría(s) del desarrollo sustentable.

La primera incertidumbre que hay que plantear, siguiendo a Latour (2005, pp. 27-42) es la idea de que la sociología estudio 'algo' que es social. Es decir, es necesario poner en entredicho que así como existen la madera o el plástico, hay algo que es social (en el sentido que la noción de 'tejido social' parece implicar). Latour sostiene que mientras que la sociología parece contentarse con clasificar a los actores (principalmente humanos) en grupos pre-establecidos, como clase o gobierno, si uno se limita a observar a dichos actores, sus movimientos, sus conexiones, da la sensación de que esas clasificaciones limitan nuestro entendimiento en lugar de profundizarlo. Lo que uno observa cuando se toma al mundo como fuente de asombro no es la co-existencia, más o menos armónica, de grupos sino la constante, fluida, inestable y cambiante formación -y quiebre- de agrupaciones. Así, Latour señala que "la primera fuente de incertidumbre de la que uno debe aprender es que no hay grupo relevante del que puede decirse que construye agregados sociales, ningún componente establecido que puede ser usado como un punto de partida incontrovertible (...) Todo lo contrario: el punto de partida [del análisis sociológico] comienza precisamente con las controversias acerca de a cuál agrupamiento uno pertenece, incluyendo por supuesto las controversias entre científicos sociales acerca de qué está hecho el mundo" (Ibídem,2005, p. 29).

La segunda incertidumbre que la teoría sociológica clásica ha escondido se refiere a qué determina la acción. Cualquier observación de una acción permite darnos cuenta que la voluntad individual del sujeto no parece ser su única fuente. El ojo sociológico puede dar cuenta de limitantes y determinantes de la acción que, de alguna manera, no están bajo el control de quien actúa. Pero asumir que la acción está sobredeterminada no es lo mismo que- ni requie- 
re necesariamente - argumentar que existe algunas fuerzas sociales (como el inconsciente o el habitus) que expliquen esa acción. Sí, en cambio, nos fuerza a hacernos una pregunta que es a la vez más trivial y más difícil de responder: ¿qué y quiénes actúa(n) cuando estamos viendo una acción? Cuando se estudian acciones deben identificarse los actores y, de ese modo, se descubrirá fácilmente que "un actor es aquél -o aquello- que es hecho actuar por otros" (Ibídem 2005, p. 46). Bajo este postulado, todo actor no es un agente individual, sino un entramado de personas y objetos que se conectan para producir una determinada acción. Esta concepción del actor como red tiene la consecuencia de dislocar la acción, de distribuirla, no necesariamente de forma homogénea, entre varios componentes que se interrelacionan.

La dislocación de la acción tiene, a su vez, una consecuencia de fundamental importancia para la TAR y, como consecuencia, para el tratamiento de la relación entre humanos y no-humanos. Esta consecuencia es que los elementos de las redes, y especialmente los materiales, no son meros intermediarios que 'transmiten' la intención de algunos de los actores. Son, por el contrario, mediadores, es decir, actores que por sí mismos tienen la capacidad de producir efectos, en ocasiones diferentes a aquellos que los actores con intenciones (humanos) buscan producir. ${ }^{2}$ Un ejemplo sencillo bastará. Cuando se destinan zonas de bosques a la producción maderera, los árboles pueden ser considerados objetos que simplemente responden a la intencionalidad de algunos actores (gobiernos que buscan generar empleos, empresas que buscan producir ganancias). Sin embargo, esos árboles -o la ausencia de ellos, para ser más exactos- puede producir la desertización de la zona, dando lugar a inundaciones u otros desastres 'naturales'. ¿Quién quería producir ese efecto? ¿El político? ¿El empresario? La falta de árboles es la causa (que, a su vez, puede tener otras causas) y, por ello, es necesario que se considere a un actor no-humano (el árbol) como un agente capaz de producir efectos en las redes en las cuales se inserta. El árbol no es un mero intermediario entre el producto maderero y el consumidor o entre el político y el votante, sino un

\footnotetext{
${ }^{2}$ La noción de mediación ha sido profundizada por los teóricos de TAR y han propuesto la idea de traducción como concepto que diferencia el papel del intermediario (como el elemento que sólo transporta causalidad) del de mediador (como el elemento que transporta transformaciones o que, en suma, conecta dos actores con diferentes efectos en cada red en la que se inserta).
} 
mediador que es capaz de producir efectos que no fueron buscados por nadie y con consecuencias para todos.

Lo antedicho nos pone de lleno frente a la tercera incertidumbre, ¿̇quién/qué tiene agencia? Si agencia es la capacidad de actuar con intención, es obvio que sólo los humanos serían poseedores de esta habilidad. Si agencia, en cambio, es la posibilidad de causar efectos, entonces los humanos comparten con muchísimos no-humanos (desde computadoras hasta ríos) esta capacidad. ${ }^{3}$ Este planteo, que se enfrenta a buena parte de la filosofía occidental, no sólo es consecuencia de las dos incertidumbres previas, sino que es lógica conclusión de observar que las relaciones sociales siempre tienen -y requieren- un entramado material que le dé sustento, que las haga extensivas en tiempo y espacio, que las localicen en situaciones específicas. Por esta razón Latour (1991) ha argumentado que la tecnología es la sociedad hecha para que dure. No existe un conjunto de actores sociales y un conjunto de elementos materiales, sino que hay asociaciones específicas, situadas, que agrupan agentes de diversa naturaleza. Algo es social no cuando está hecho de un material abstracto e inobservable - como la clase- sino cuando ensambla elementos variados para producir determinado efectos. Esos elementos, en sí mismos, no son ni pueden ser sociales.

La cuarta incertidumbre se podría formular de la siguiente manera, ¿no hay algo que pueda concebirse como 'más allá' de toda controversia y que, por ello, sirva como sustento para el conocimiento objetivo, sea natural o social? Esta pregunta se puede formular de una forma más filosófica, ¿̇existen cuestiones de hecho (matter of facts), además de cuestiones de interés (matter of concerm)? La pregunta tiene la intención de cuestionar si los actores de las redes tienen el mismo status ontológico y epistemológico, o, más precisamente, si 'lo social' y 'lo natural' son expresiones que tengan valor explicativo. La respuesta de Latour (Ibídem 2005, pp. 110-120) es que tanto la idea de naturaleza como la de sociedad han sido creaciones modernas que "no describen ningún dominio de la realidad, sino que son colectores que fueron inventados conjun-

${ }^{3}$ Latour (2005, p. 71) recomienda a los sociólogos hacerse la siguiente pregunta para determinar si en su explicación de un fenómeno un objeto - o conjunto de objetos- juega un papel de actor: chace alguna diferencia en el curso de la acción de otros actores o no? ¿Hay alguna prueba que le permita a alguien detectar esta diferencia? En otras palabras, lo que Latour busca es que nos preguntemos sobre la relevancia del objeto como mediador en la red que estamos describiendo. Si la tiene, debe ser un actor más de nuestro relato. Si no, puede excluirse. 
tamente, por razones mayoritariamente polémicas, en el siglo XVII" (Ibídem 2005, p. 110). Por colectores Latour entiende una red cuyos elementos constitutivos y sus relaciones se han estabilizado a tal punto que se han vuelto una caja negra, un ente incapaz de ser observado, descrito y criticado por nadie. El problema, sin embargo, es que los estudios de la ciencia primero, y la sociología de las asociaciones luego, se han dedicado a desarmar esas redes, a mostrar hasta qué punto son construcciones socio-técnicas y, por lo tanto, ensamblados contingentes. Para eso, los estudios de la ciencia se han concentrado en las controversias, es decir, en los momentos en los cuales una parte de la realidad está en disputa entre dos o más grupos y, por lo tanto, la realidad en sí misma no puede ser usada como elemento para finalizar el desacuerdo. Estos momentos permiten observar claramente que lo que con el tiempo se volverá un hecho ha sido, en buena medida, un apasionado debate, un desencuentro de intereses que, sin embargo, en algún punto culminó y adquirió status de real. ${ }^{4}$ Una consecuencia ética, política y de valor teórico es que cuando se acepta que la realidad es una cuestión de interés,

no podemos estar ya satisfechos ni con la indiferencia hacia la realidad que va con múltiples representaciones simbólicas de la misma naturaleza ni con la prematura unificación provista por la 'naturaleza'. Al incluir los múltiples resultados de las ciencias en el zoológico de las agencias presentes en forma conjunta en el mundo, hemos cruzado otro Rubicón, uno que va de la metafísica a la ontología. (ibídem 2005, p. 117)

De este modo, nos alejamos de una concepción en la cual el mundo -la realidad- es uno, allí afuera, al que podemos observar e interpretar desde diferentes puntos de vista y nos adentramos en una ontología que nos permite pensar que el mundo en sí mismo permite ser usado de forma múltiple, variada, indeterminada, sorpresiva (Berg y Mol 1998; Mol 2003), de forma tal que las asociaciones que se producen son un subgrupo de todas las que (potencialmente) podrían tener lugar. La aceptación de que una noción de la realidad en forma de red es una cuestión ontológica y no epistemológica abre

\footnotetext{
${ }^{4}$ Retrospectivamente siempre es más fácil ver que lo que se pensó que era un hecho, no ha sido otra cosa que una cuestión de interés(es) de ciertos grupos. Latour, por ejemplo, sostiene que "los espermatozoides solían ser obstinados pequeños machos que nadaban con fuerza hacia el indefenso óvulo; ahora ellos son atraídos, enrolados, y seducidos por un huevo cuya agencia está volviéndose tan sutil que puede seleccionar el buen esperma del malo o al menos esto es lo que ahora está siendo disputado en la fisiología del desarrollo" (Ibídem 2005, p. 116. Ver también Strum y Fedigan 2000)
} 
la puerta a la política ontológica (Law 2006; Rodriguez Medina 2009), es decir, al compromiso con mundos alternativos.

Tomada en serio, una política ontológica es un compromiso con el armado (enactment) de redes (realidades) alternativas, de mundos posibles, de caminos diferentes a los ya explorados. Pero aquí se abre, consecuentemente, la quinta incertidumbre. ¿Quién está a cargo de este proceso? ¿Quiénes pueden armar nuevas realidades? Latour sostiene que esta pregunta nos fuerza a cuestionarnos la naturaleza de los reportes (accounts) que componen la cotidianeidad de los científicos y que, al final del día, es la forma en que éstos/as contribuyen a dar forma a nuevos entramados de objetos y seres humanos. En su visión del reporte científico, Latour argumenta que la diferencia central entre las ciencias naturales y las sociales no es el uso de matemática, modelos formales, gráficos complejos y tablas con datos cuantitativos. La diferencia es que mientras las ciencias naturales pueden nunca pueden 'hacer callar' a sus objetos de estudio, a los elementos que componen su quehacer. ¿Cómo ignorar que la luz se comportó de determinada manera? ¿Cómo dejar de lado que los fenotipos de las crías se asemejan a los de sus padres? Imposible. En cambio, no parece ser difícil para las ciencias sociales ignorar la voz de sus sujetos de investigación. ¿La forma de hacerlo? A través de hacer encajar las respuestas de informantes, las observaciones, los testimonios en metalenguajes científicos que, en última instancia, parecen no necesitar datos empíricos. ¿Cómo desestimar las palabras de un creyente que sostiene que sus acciones responden a la voluntad de Dios? Fácilmente: reduciendo la religión a un fenómeno 'social' que, como tal, debe ser explicado por fuerzas tales como el súper-yo o las clases sociales, conceptos que aunque son tan abstractos como la voluntad de Dios forman parte del vocabulario aceptado y compartido del investigador social. En términos más generales, los reportes de los científicos sociales son menos 'objetivos' que los de sus contrapartes de las ciencias naturales sencillamente porque reducen (mediante una transformación lingüística) la multiplicidad y complejidad de fenómenos observados a algunas fuerzas 'sociales' que tienen la capacidad de explicarlo casi todo.

Lo anterior permite visualizar cuál es la idea de papel del científico social en la TAR: "extender la exploración de las conexiones sociales un poco más" (Latour 2005, p. 128). La función del investigador social es rastrear los trazos 
que han dejado las conexiones entre actores, por lo que involucra mirar todos los mediadores de las redes, los humanos y los no humanos. Por eso Latour afirma que "si lo social es un rastro, entonces puede ser rastreado; si es un ensamble, entonces puede ser re-ensamblado" (Ibídem 2005, p. 128). Yluego agrega,

un buen reporte de TAR es una narrativa o una descripción o una proposición en la cual todos los actores hacen algo, y no están sólo allí sentados. En lugar de simplemente transportar efectos sin transformarlos, cada uno de los puntos en el texto se vuelve una bifurcación, un evento, o el origen de una nueva traducción. Tan pronto como los actores son tratados no como intermediarios sino como mediadores, ellos vuelven al movimiento de lo social visible para el lector (Ibídem)

Lo anterior permite concluir que una red no es sencillamente algo que existe en el mundo y tiene forma de puntos interconectados (como la red de metro). En cambio es "un indicador de la calidad de un texto acerca de un determinado tema" (ibídem 2005, p. 129). Una red es producto del texto que le da forma y, por eso mismo, la red en sí misma muestra de qué manera los actores hacen actuar a otros actores, especialmente de forma imprevista. Por ello, "un buen texto establece (elicit) redes de actores cuando le permite al científico rastrear el conjunto de relaciones definido como múltiples traducciones" (ibídem 2005, p. 129).

Este repaso por la teoría de actor-red nos ha permitido cuestionar supuestos básicos de las ciencias sociales tradicionales. En particular nos ha mostrado que (a) lo social es una conexión entre elementos que, en sí mismos, no tienen nada de social, (b) la acción está sobredeterminada, (c) los objetos tienen agencia, al menos en término de producir efectos, (d) no hay hechos duros, sino cuestiones de interés entre redes que compiten por definir qué -y cómo- es la realidad y (e) los científicos contribuyen a crear redes y, por ello, son artífices del proceso mismo de construcción de la realidad.

\section{De redes y desarrollo}

Existen numerosos paradigmas para comprender el desarrollo sustentable. Gutiérrez Garza y González Gaudiano (2010) argumentan que se pueden mencionar al menos cinco: economía de frontera, protección ambiental, manejo 
de recursos, ecodesarrollo y ecología profunda. ${ }^{5}$ De cada uno, a su vez, es posible identificar su imperativo dominante, amenazas dominantes, la relación entre seres humanos y naturaleza, los temas principales, los regímenes de propiedad que defienden, los actores que cargan con la implementación de sus políticas, la responsabilidad por el desarrollo de la administración, las tecnologías y estrategias de gestión ambiental, las metodologías analíticas para la modelación y la planeación y las fallas fundamentales (ibídem 2010, pp. 181182).

Interesante como es, el debate entre paradigmas esconde que detrás de cada uno hay una teoría social que le da sustento, que la conecta con presupuestos epistemológicos (por ejemplo, ¿̇ómo se conoce la naturaleza?) y ontológicos (por ejemplo, ¿qué status tiene el ser humano en la transformación del planeta?). Gutiérrez Garza y González Gaudiano no entran en estas cuestiones pero creemos que no pueden ignorarse porque su aceptación o rechazo como modelos de desarrollo depende, en buena medida, de que sean percibidos en el contexto de teorías más amplias.

Los paradigmas de economía de frontera (EF) y de ecología profunda (EP) aparecen como los polos, porque presentan posiciones extremas (niveles de radicalización) en relación a todos los criterios antes mencionados. En este apartado veremos de qué manera EF responde a la teoría social tradicional - de influencia positivista- mientras que la EP reclama cambios que, en su mayor parte, van de la mano con lo sugerido por TAR. Veremos, por otro lado, que este paradigma no ahonda en el papel de lo no-humano que no es biológico, es decir, en la tecnología, lo cual puede percibirse como una de sus mayores debilidades.

Para Gutiérrez Garza y González Gaudiano la EF tiene como imperante el progreso bajo el presupuesto de que el crecimiento económico es infinito. Este postulado considera que los recursos naturales no son un factor que pueda detener el progreso, aún cuando puede forzar a redireccionamientos (por ejemplo, el uso de nuevas formas de energía). Esta postura hacia los recursos humanos conlleva un antropocentrismo muy marcado, ya que el hombre aparece como el motor del progreso, como el agente que produce y que tiene la facultad de cambiar. El antropocentrismo trae como consecuencia que las

\footnotetext{
${ }^{5}$ Esta tipología se basa en Colby (1991).
} 
amenazas principales que el paradigma determina se enfocan sobre los seres humanos (hambre, pobreza y enfermedad) y se concibe a la naturaleza básicamente como posible fuente de desastres naturales. Frente a un panorama de recursos escasos - pero potencialmente ilimitados para el crecimiento- el tema principal de este paradigma es el libre acceso a esos recursos y su explotación. A menudo este tema es traducido en las estrategias empresarias y gubernamentales para ir adquiriendo paulatina pero continuamente mayores espacios naturales para extracción de materias primas. De alguna manera, y parafraseando a Heidegger, este paradigma toma al planeta como un reservorio de energía para explotación. Existen dos regímenes de propiedad básicos para este paradigma: la privatización (propiedad de los recursos naturales por parte de personas físicas o morales) y la estatización (propiedad de los recursos naturales por parte del estado).

El paradigma de EF considera que los costos de la política ambiental cae sobre los propietarios que, en general, se traduce en el gran público y, por lo tanto, en los sectores más desfavorecidos. Pero son también los propietarios los responsables de la administración del desarrollo. Aquí se plantea una diferencia entre la teoría y la práctica. En la teoría, la propiedad privada de los recursos produce que los propietarios sean responsables del uso de los recursos, por lo que son también quienes pagan y quienes obtienen los beneficios. Sin embargo, en la práctica, las cargas están descentralizadas entre propietarios grandes y pequeños, entre el empresario y el vecino, mientras que los beneficios están centralizados en los primeros, debido a su poder de compra, a la capacidad de concentración del capital y los recursos y a la tendencia monopolista de los regímenes capitalistas.

La gestión ambiental para el paradigma EF se basa en la industria, con altos consumos de energía, producción mecanizada, dispersión de la contaminación y falta de regulación, especialmente en lo referente a la eliminación de residuos. Este paradigma se apoya en la idea de libre mercado y en la noción de autorregulación, asumiendo que un uso indebido -o exagerado- de cualquier recurso tiene como punto final la imposibilidad de continuar con el proceso productivo. Por ello, las metodologías analíticas de planeación descansan en modelos de sistemas cerrados, de equilibrio (ya sea con o sin intervención del estado), que consideran que la producción está limitada por factores no 
humanos (capital) pero no por los recursos naturales, que generalmente no se contabilizan. En pocas palabras, el análisis central es de costo-beneficio de bienes y servicios, por lo que tomar en cuenta los recursos naturales aparece como innecesario (al menos hasta que se perciba su agotamiento). Como corolario, este paradigma defiende una concepción mecanicista de la producción, de la sociedad y de la naturaleza, con escasa consideración del balance ecológico.

La posición más radicalizada es el paradigma de EF, que en general presenta desafíos generales a la concepción más economicista del desarrollo sustentable. El imperativo dominante es el anticrecimiento, basándose en la idea de que la armonía con la naturaleza demanda prácticamente la no intervención humana. Por eso, tiene en cuenta en un papel central a los elementos bióticos no humanos (biocentrismo), pero bajo la idea de que la dimensión natural de los seres vivos es la que debe ser protegida y desarrollada. En este sentido, sin negar el impacto que los desastres naturales puedan tener para los seres humanos, considera como principales amenazas al colapso del ecosistema per se, es decir, a los desastres provocados. Mientras los desastres naturales son, de alguna manera, reajustes del ecosistema en busca de nuevos equilibrios, los desastres provocados son situaciones que impactan negativamente en los ecosistemas, que muchas veces no tienen elementos para generar tendencias inversas o revertir los daños. Por eso mismo el tema principal del paradigma es el retorno a la naturaleza, una suerte de simbiosis simple que ponga al ser humano en el contexto de ecosistemas escasamente transformados o, en otras palabras, tecnológicamente sencillos.

En relación a la propiedad, el paradigma de EF defiende la propiedad privada, pero agrega una forma de propiedad colectiva o común que está destinada a la conservación de la naturaleza. Es una forma de propiedad que busca que ciertos ecosistemas, por razones ecológicas, se preserven de la forma más natural posible. En este sentido, el costo de una política ambiental se evita, al tener como objetivo abstenerse del desarrollo o, dicho de otra manera, al buscar que vastas regiones queden intactas. La responsabilidad del desarrollo, por otro lado, aparece como descentralizada, involucra al gobierno, a los ciudadanos, a las corporaciones y a las organizaciones de la sociedad civil, pero 
se orienta a una postura preservacionista en la que la responsabilidad aparece como sinónimo de auto-exclusión.

Bajo este modelo de propiedad y frente al imperativo del no desarrollo, la relación con la tecnología es compleja. En principio, se defiende una economía de escala reducida, en la que las personas vivan en comunidades más o menos autosustentables en término de los recursos para su consumo, con necesidades materiales simples y con sistemas tecnológicos autónomos. En este paradigma se respeta y fomenta un uso no científico de la tecnología. Por uso no científico de la tecnología nos referimos en el contexto de este trabajo a una consideración, respeto, fomento y exploración de formas de desarrollo tecnológico basadas en las experiencias sociales y culturales específicas de cada comunidad, tomando en cuenta su pasado, sus necesidades, y su relación con el entorno material y social. El uso del agua a partir de técnicas milenarias por parte de ciertos pueblos indígenas sería un ejemplo. Esto tiene como lógica consecuencia que, en relación a las metodologías de modelación y planeación, se piensa a un nivel biorregional, donde se busca conservar la diversidad biótica y cultural, a la vez que fomentar y reproducir la autonomía de las comunidades.

Entre los problemas que este paradigma tiene está, por un lado, la idea de que es necesaria una reducción de la población, así como un cambio profundo en su organización social (más comunitaria) y económica (con necesidades materiales más simples). Por otro lado, tiene una concepción de la tecnología simplista, que está asociada a cierto cientificismo que de ninguna manera es la única forma de comprender este lado material de la vida humana.

La breve y esquemática descripción de cada uno de estos paradigmas extremos nos lleva a cuestionarnos las conexiones que estas conceptualizaciones del desarrollo sustentable tienen con la teoría social. En particular, cabe poner en juego cada una de las cinco incertidumbres descritas en la sección anterior para poder vincular estos paradigmas con el modelo de la ciencia social tradicional, lo que Latour llama 'sociología de lo social' y con el modelo de la ciencia social propuesta por TAR, o 'sociología de las asociaciones'. Estas conexiones están resumidas en la tabla 1.

En relación a concebir lo social como una asociación, la ecología profunda se distingue de la economía de frontera. Mientras ésta concibe a la sociedad 


\begin{tabular}{|l|l|l|}
\hline Criterio & Economía de Frontera & Ecología Profunda \\
\hline Lo social como asociación & $\begin{array}{l}\text { No, la economía y la sociedad tienen } \\
\text { leyes propias }\end{array}$ & $\begin{array}{l}\text { Sí, la economía y la sociedad son resul- } \\
\text { tados de las relaciones con los ecosiste- } \\
\text { mas }\end{array}$ \\
\hline Sobredeterminación de la acción & Sí, por las estructuras económicas & Sí, por los ecosistemas \\
\hline Objetos con agencia & $\begin{array}{l}\text { No, la tecnología es un producto del } \\
\text { desarrollo científico }\end{array}$ & $\begin{array}{l}\text { No, la tecnología es un producto del } \\
\text { desarrollo científico }\end{array}$ \\
\hline $\begin{array}{l}\text { Cuestiones de hecho y cuestiones de } \\
\text { interés }\end{array}$ & $\begin{array}{l}\text { Las leyes de la economía y la sociedad } \\
\text { (capitalistas) aparecen como hechos }\end{array}$ & $\begin{array}{l}\text { Las leyes de la economía y la socie- } \\
\text { dad (capitalistas) aparecen como con- } \\
\text { tingentes }\end{array}$ \\
\hline Papel del investigador social & $\begin{array}{l}\text { Descriptivo de las relaciones socio-eco- } \\
\text { nómicas }\end{array}$ & $\begin{array}{l}\text { Prescriptivo, transformación de la so- } \\
\text { ciedad }\end{array}$ \\
\hline
\end{tabular}

Cuadro 1: Tabla 1: Comparación entre los paradigmas de Economía de Frontera y de Ecología Profunda en función de las incertidumbres planteadas por TAR. Fuente: elaborado a partir de Gutiérrez Garza y González Gaudiano (2010, pp. 122-194)

-y por consecuencia a la economía- como una entidad que tiene relaciones y leyes propias y tiende a un equilibrio autoorganizado, la ecología profunda sostienen que la economía y la sociedad deben pensarse en contacto con los ecosistemas de los cuales son parte. Los ecosistemas presentan limitaciones para el desarrollo social y económico y, como tales, introducen relaciones que no pueden dejarse de lado. $\mathrm{O}$, mejor dicho, relaciones que si son ignoradas ponen en riesgo la continuidad -sustentabilidad- de cualquier régimen social o económico.

En el mismo sentido, los ecosistemas son entes que sobredeterminan la acción individual, cumpliendo el mismo papel que las estructuras económicas y sociales juegan en la concepción de la EF. Así, cuando se analizan los márgenes de acción que tiene una persona o un grupo, ambos paradigmas limitan fuertemente cualquier concepción individualista y racional de la decisión. El problema, sin embargo, es que ecosistemas y estructuras socio-económicas aparecen como elementos explicativos, es decir, como colectores (Latour 2005) que aparecen como cajas negras imposibles de desarticular, para poder observar de qué manera dichos colectores son, en buena medida, producto de mediadores - humanos y no humanos- actuando en forma de redes.

La división entre cuestiones de hechos y de interés también distingue ambos paradigmas. La EF sostiene que las leyes de la economía y la sociedad capita- 
listas son hechos que no pueden alterarse. Expresiones como " $x$ es explicado por la demanda de $y$ " presenta, implícitamente, la idea de que 'la demanda de y' es un hecho y, como tal, se impone al investigador e incluso a los actores que están vinculados a ese proceso. Convertir a una cuestión de interés en una cuestión de hecho, en un dato (primero) y en un hecho (posteriormente) es un proceso que los estudios de la ciencia llaman 'cajanegrización' (Latour 1999). Volver a un proceso -y sus partes componentes- una caja negra no es otra cosa que excluirlo del ámbito de las controversias, lo debatible, lo negociable, y dejarlo en el ámbito de lo incuestionable, lo aceptado. Cuando este procedimiento es exitoso, actuar 'contra' las cajas negras se vuelve incluso irracional. Por eso no nos puede sorprender que algunos actores que apoyan la globalización neoliberal digan frecuentemente que negar la globalización (ahora sin el adjetivo neoliberal) es actuar irracionalmente. El paradigma de la EP, en cambio, basa sus postulados más fuertes en una negación de muchos de los presupuestos de la EF. En algún sentido, la EF considera que es necesario 'descajanegrizar' lo que la economía neoliberal ha vuelto cuestiones de hecho, datos 'duros', y adaptarlos a modelos de sustentabilidad diferentes. La mera afirmación de que es necesario un estilo de vida menos dependiente de lo material y una vuelta a lo 'natural' es un intento de cuestionar las leyes del progreso que la sociología y la economía tradicionales han convertido en hechos ineludibles del desarrollo humano. El éxito de este proyecto alternativo, depende, en buena medida, de reconceptualizar la idea de tecnología, como veremos unos párrafos más abajo.

Al diferir en lo referente a la idea de lo social y las cuestiones de hecho/interés, los dos paradigmas tienen una concepción diferente del papel del investigador social. Mientras que la EF le asigna al investigador la tarea de describir las 'leyes naturales' de la economía y la sociedad (capitalistas), la EP le da al investigador parte de la responsabilidad de construir una realidad alternativa y sustentable. ¿De qué manera el investigador puede cumplir con este mandato? En primer lugar, con imaginación, es decir, con análisis que propongan nuevas conexiones entre humanos y no-humanos, nuevas redes que no hayan sido exploradas. Un ejemplo es la consideración de formas tradicionales de utilización de recursos naturales, como la medicina y las técnicas de riego indígenas. En segundo lugar, con aceptar que las redes que se 
propongan están compitiendo con otras redes -frecuentemente más poderosas- que intentan consolidar realidades diferentes (por ejemplo, la globalización neoliberal) pero que no son más que cuestiones de interés. En otras palabras, propuestas alternativas no deben ser vistas como meras opiniones desviadas que no aceptan la 'realidad' de las actuales tendencias sociales y económicas, sino que ambas redes semiótico-materiales que buscan dar forma a la realidad en función de ciertos intereses y modelos de desarrollo. Finalmente, los investigadores tienen que tomar en serio el proceso de cajanegrización y, sobre todo, el papel de los actores no-humanos en la configuración y expansión de las redes. En relación a esto, por lo tanto, la estrategia es doble. Por un lado, cuestionar aquello que las redes en competencia tratan de mostrar como datos duros o hechos incuestionables y demostrar hasta qué punto son cuestiones de interés de ciertos actores (nuevamente humanos y no humanos) que tienen un determinado modelo de sociedad. Por el otro, utilizar a-y respetar la voz de- los actores no humanos que forman parte de toda realidad, tales como ríos, bosques, modelos estadísticos, dinero, y tecnologías de medición. Lo que estos elementos 'digan’ puede llegar a ser mucho más sólido $-\mathrm{y}$ difícil de ignorar- que lo que los humanos afirmen, incluso si pertenecen a poderosas organizaciones como Greenpeace.

A pesar de estas diferencias, hay un aspecto en el que los paradigmas de la economía de frontera y la ecología profunda coinciden: en la falta de agencia de los objetos. Para ambos modelos, la tecnología (la actividad de producción de objetos) da lugar a elementos que quedan a merced de los actores humanos, que son los que deciden su utilización. Para ambos paradigmas la tecnología aparece como resultado del desarrollo científico y, por ello, le asignan cierta neutralidad que sólo se altera a partir de su uso. Esta concepción positivista de la tecnología tiene dos importantes consecuencias (Bunge 2001). En primer lugar, coloca a la tecnología como un paso lógicamente posterior al devenir científico pero aceptando que la ciencia es la actividad europeocéntrica que se describe en los textos de metodología de la investigación (Santos 2009). Ciencia es hipótesis testeadas, teorías, metodologías preferentemente cuantitativas y modelos que simplifican la realidad. Desde este punto de vista, la tecnología es la aplicación de las verdades científicas universales a diferentes ámbitos de la vida humana, desde el derecho y la psicología clínica a la 
hidráulica y la física de materiales. En segundo lugar, la tecnología goza de neutralidad porque, en sí misma, no tiene ningún programa de aplicación prediseñado. Un cuchillo puede usarse para comer, pero también para matar, por lo que los filósofos de la tecnología positivista han considerado que el cuchillo, en sí mismo, no es bueno ni malo, sino útil o inútil para ciertos fines, exclusivamente definidos por seres humanos.

Esta concepción ha sido fuertemente criticada por los estudios de la ciencia (Ihde 1991, 2003; Latour 1988, 2005; Callon 1986; Law 1986). Sin entrar en detalles técnicos, los estudios recientes de la ciencia y la tecnología han planteado que los instrumentos son, en sí mismos, resultados de la agrupación de personas (por ejemplo, científicos, filántropos, estudiantes doctorales) y de objetos (por ejemplo, madera, metales, tornos, computadoras). La manera en que estos elementos se configuran depende de las estrategias que algunos de ellos desarrollan, aquellos que Latour $(1987,1988)$ ha llamado 'traductores'. Los traductores son los actores que han logrado expresar la voluntad o deseos de otros en sus propios términos y, por ello, se vuelven elementos clave dentro de las redes. Siguiendo este razonamiento, se vuelve obvio que ciertos objetos - como una bomba atómica- contienen en su lógica de construcción los intereses de ciertos actores humanos (por ejemplo, militares) y no humanos (por ejemplo, uranio) y sólo si se coordinan en redes logran su objetivo final.

En lo que respecta a los paradigmas de desarrollo sustentable, la tecnología aparece como un elemento que es intrínsecamente externo a los seres humanos y que éstos utilizan para el progreso material (EF) o para deteriorar los ecosistemas (EP). Implícitamente, ambos paradigmas sostienen que la tecnología es neutral pero su uso puede contribuir a solucionar o empeorar los problemas producidos por los seres humanos en su interacción con la naturaleza. Más aún, ambos paradigmas tienen una idea de la naturaleza como aquello que no ha sido transformado por el hombre. Ambas tesis son, según los recientes estudios de la ciencia, cuestionables. Por un lado, la tecnología no es neutral, sino el resultado de redes socio-técnicas que tienen intereses a nivel de sus actores constitutivos y de la propia red una vez que ésta está en funcionamiento. Dicho en un tono más directo, hay tecnologías que han sido concebidas sin ningún tipo de consideración por el medio ambiente y, como tales, no puede pensarse que hay formas de conciliarlas con modelos de desa- 
rrollos sustentables ecológicamente responsables. Por otro lado, la naturaleza no es algo externo que el hombre apropia, destruye, transforma. La naturaleza, como la sociedad, son construcciones socio-técnicas detrás de las cuales se esconden presupuestos ontológicos siempre cuestionables. La naturaleza, especialmente tal como la conocemos en la actualidad, ha sido el producto de las investigaciones científico-tecnológicas que el hombre ha emprendido por siglos. Sin el velo realista que nos fuerza a pensar que los científicos sólo describen una realidad objetiva, y defendiendo una ontología relativista y relacional (Law 2006) debemos aceptar que esos actores han sido capaces, en sus laboratorios, de crear naturaleza, de establecer relaciones cada vez más complejas y sofisticadas que van arrojando naturalezas diferente.

\section{Una breve conclusión}

Un paradigma aún más radicalizado que el de la Ecología Profunda (Gutiérrez Garza y González Gaudiano 2010) debería contemplar tres cambios en sus presupuestos ontológicos y epistemológicos. En primer lugar, una concepción no científica de la tecnología, es decir, una idea de la tecnología como ensamblado socio-técnico que incorpora actores humanos y no humanos y que, por ello, puede adoptar la forma de una red que sea respetuosa de tradiciones culturales y cognoscitivas alternativas al modelo científico europeocéntrico. En segundo lugar, el paradigma debería contemplar la agencia de los objetos y, a partir de eso, tomarse en serio las formas en que los factores a-bióticos de los ecosistemas también pueden transformar a los seres humanos. Asignar agencia a los objetos - sean o no creados por el hombre- puede dar lugar a estudiar rastros, huellas, que hasta aquí han sido ignorados y, mejor aún, proponer nuevas asociaciones que den lugar a prácticas ecológicamente sustentables. En tercer lugar, una radicalización del paradigma de desarrollo sustentable tiene que pasar a través de la lente de la hipersimetría por la que atravesaron los estudios de la ciencia. Y eso quiere decir ni más ni menos que aceptar que la naturaleza en sí misma es una construcción socio-técnica, que como tal puede transformarse pero que, precisamente por ello, no puede usarse como el elemento de cierre de controversias. De nada sirve creer que la preservación de la naturaleza es un objetivo que servirá, per se, para agrupar a todos los actores humanos y no humanos relevantes, desde gobiernos y empresas hasta man- 
glares, larvas y represas. La preservación de la naturaleza es un proceso que incluye cuestionar(nos) qué es preservar (por ejemplo, ¿no modificar? ¿Modificar en forma sustentable? ¿Modificar pero comprendiendo los costos?) y qué es la naturaleza (por ejemplo, ¿̇sólo lo que no ha sido usado por el hombre? ¿Lo que fue usado pero no transformado? ¿Lo que ha sido transformado en forma sustentable?).

Lo natural debe ser concebido en los mismos términos que lo social. No como algo en sí mismo (como una entidad) sino como un conjunto de relaciones que arrojan como resultado que algo sea considerado 'natural'. Lo social requiere lo natural, como lo sabe el cantante de ópera que espera que sus cuerdas vocales estén en perfecto estado al momento del concierto. Pero lo natural requiere lo social, como lo sabe la madre que aplica vacunas a su hijo para transformarle el sistema inmunológico y, de ese modo, garantizar su salud. Este idea y vuelta entre lo social y lo natural como entramado socio-técnico tiene más potencial que el uso de ambas categorías - sociedad y naturaleza- como factores explicativos y cajas negras cuyas estructuras internas se esconden para el investigador. Ese potencial descansa en que la verdadera radicalización de un modelo de desarrollo sustentable no es volver a la naturaleza (dado que ésta misma debe ser cuestionada) sino proponer, defender y extender redes que involucren actores humanos (como los activistas) y no humanos (como las ballenas, los microbios y las computadoras) y que se relacionen entre sí de forma sustentable. En suma, sustentabilidad es una propiedad de las redes por la cual todo aquellos que circula por sus nodos -desde información a energía- debe poder continuar haciéndolo en el futuro sin depender de la incorporación de elementos exógenos para su funcionamiento. Cuando una red crezca lo hará bajo el presupuesto de que los nuevos elementos han sido enrolados para la expansión de la red, pero dicha expansión incluirá necesariamente la continuidad de todos y cada uno de sus miembros. La configuración de estas redes dependerá, en buena medida, de cuán originales seamos para pensarlas y cuán éticamente comprometidos estemos para ser parte de ellas.

\section{Referencias}

Callon, M., 1986, "Some elements of a Sociology of Translation: Domestication of the Scallops and the Fishermen of St. Brieuc Bay", en J. Law (Ed) Power, Action, and Belief: A New Sociology of Knowledge?, Keele, Sociological Review Monograph. 
Colby, M. E., 1991, "La administración ambiental en el desarrollo: evolución de los paradigmas”, El trimestre económico, 231, pp. 589-615.

Golinski, J., 2005, Making Natural Knowledge. Constructivism and the History of Science, Chicago, University of Chicago Press.

González Gaudiano, E., 1998, Centro y Periferia de la Educación Ambiental. Un enfoque antiescencialista México,Mundi Prensa México.

Guha, R. y Martínez-Alier, J., 1997, Varieties of Environmentalism: Essays North and South, Londres, Earthscan.

Gutiérrez Garza, E. y González Gaudiano, E., 2010, De las Teorías del Desarrollo al Desarrollo Sustentable, México, Universidad Autónoma de Nuevo León y Siglo XXI.

Ihde, D., 1991, Instrumental Realism. The Interface between Philosophy of Science and Philosophy of Technology, Bloomington, Indiana University Press.

— sophy of Technology: The Technological Condition. An Anthology, New York: Blackwell.

Jimenez Herrero, L. M., 2000, Desarrollo Sostenible. Transición hacia la Coevolución Global, Madrid, Pirámide.

Kerz, M., (comp), 2009, El Dominio Político: permanencias y cambios. Aportes para una reflexión teórica, Buenos Aires, Teseo.

Latour, B., 2005, Reassembling the Social. An Introduction to Actor-Network Theory, Oxford, Oxford University Press.

—, 1999, Pandora's Hope: Essays on the Reality of Science Studies, Cambridge, MA, Harvard University Press.

__ 1991, "Technology is Society Made Durable”, en Law 1991, pp. ??

—, 1988, The Pasteurization of France, Cambridge, MA, Harvard University Press.

- 1987). Science in Action. How to Follow Scientists and Engineers through Society, Cambridge, MA, Harvard University Press.

Law, J., 2006, After Method. Mess in Social Science Research, Londres, Routledge.

Law, J. (comp.), 1991, A Sociology of Monsters: Essays on Power, Technology and Domination, Sociological Review Monograph, No. 38, Keele.

Law, J. y Hassard, J. (Eds), 1999, Actor-Network Theory and After, Londres, WileyBlackwell.

Rodríguez Medina, L., 2009, “¿Estudiar lo político o construir lo político?”, en Kerz, 2009.

Santos, B. S., 2009, Una epistemología del sur. La reinvención del conocimiento y la emancipación social, CLACSO y Siglo XXI, México.

Sismondo, S., 2004, An Introduction to Science and Technology Studies, Singapur, Blackwell Publishing.

Recibido el 2 de Febrero de 2011

Aceptado el 15 de Febrero de 2011 